\title{
Evaluation of the Influence of Surface Finishing on the Corrosion Resistance of HVOF Applied Inconel 625 Coatings on Steel
}

\author{
Mariana Sgambaro de Lorenzi ${ }^{a}$, Rafael Menezes Nunes ${ }^{a}$, Tiago Falcade $^{a}$, Thomas Clarke ${ }^{a}$ \\ ${ }^{a}$ Laboratório de Metalurgia Física - LAMEF, Universidade Federal do Rio Grande do Sul - UFRGS, \\ Porto Alegre, RS, Brazil
}

Received: November 11, 2016; Revised: October 31, 2017; Accepted: November 10, 2017

\begin{abstract}
In this work, the corrosion resistance of Inconel 625 coatings applied to AISI 4140 steel plates was evaluated. Coatings were produced by High Velocity Oxygen Fuel (HVOF) by use of two different equipment which use either kerosene (liquid) or propane (gas) as fuel. The resulting coatings were evaluated in two conditions: as-deposited and after a surface finishing process by grinding. Residual stress distributions in the coatings were characterized by X-ray diffraction and their morphology was verified through metallography and roughness measurements. Potentiodynamic polarization corrosion testing complemented their analysis. The results show a strong influence of the surface finishing process on the corrosion performance of the coatings.
\end{abstract}

Keywords: $H V O F$, Inconel 625, Residual Stresses, Corrosion Resistance

\section{Introduction}

HVOF deposition is a well-known surface coating process in which a powder material is melted by combustion of a gas or liquid fuel in an oxygen-rich atmosphere, and is then propelled at high velocity towards a substrate surface ${ }^{1}$. The method is attractive especially for its productivity ${ }^{2}$, which is high compared to other traditional coating deposition techniques (e.g. PVD or CVD). It has been widely used to protect components under conditions of wear and corrosion ${ }^{3-5}$. A wide range of metallic alloys have been used as coating material, the selection of the most adequate depending on the requirements of the protective layer.

Due to its excellent corrosion resistance ${ }^{6,7}$, Inconel 625 often appears as an option for coating steels for operation in aggressive environments, such as sea water with $\mathrm{CO}_{2}$ and $\mathrm{H}_{2} \mathrm{~S}$, especially in conditions where wear and erosion are not major issues ${ }^{8}$. For the aforementioned reasons, HVOFspraying is an attractive way of applying such coatings ${ }^{9,10}$.

HVOF processing parameters determine the final microstructure and composition of the coatings and consequently their mechanical and corrosion protection properties. Residual stress build-up in the coatings is also important; as described in ${ }^{11}$, the resulting stress state is influenced by three mechanisms: quenching of lamellas on the substrate, peening of deposited layers by spray particles, and thermal mismatch between substrate and coating during cooling. The resulting stress distribution in the coating and near surface region of the substrate will be further influenced by surface finishing methods, which are often adopted in order to improve final properties ${ }^{12,13}$.

*e-mail: rafael.nunes@ufrgs.br
In this work Inconel 625 coatings were applied by HVOF on AISI 4140 steel plates. Two different third-generation equipment were used, one based on a gaseous fuel (propane), and another that uses liquid fuel (kerosene). Coatings were analyzed both before and after a mechanical surface finishing process in order to investigate variations in the coating properties and microstructure, the levels of resulting residual stresses, and also the corrosion performance of the different coating conditions.

\section{Materials and Methods}

\subsection{Substrate}

Four annealed AISI 4140 steel plates $(120 \mathrm{~mm}$ wide, $270 \mathrm{~mm}$ long and $13 \mathrm{~mm}$ thick) were used as substrates for the application of the Inconel 625 coatings by HVOF. The measured chemical composition of the as-received steel showed all elements within the limits established by the applicable standard for this material.

Prior to coating, the substrates were pre-heated to $100^{\circ} \mathrm{C}$ in order to remove solvents and oils, then blasted during 15 minutes with alumina particles (particle size between 0.5 and $0.85 \mathrm{~mm}$ ) at a pressure of $0.5 \mathrm{MPa}$, a distance of 500 $\mathrm{mm}$ and an angle of $90^{\circ}$.

\subsection{HVOF materials and parameters}

Two different fuels were used to produce the coatings, kerosene (liquid) and propane (gas). The liquid fuel was used in a JP 8000 equipment with a water-cooled 5220 model D-gun, both manufactured by Praxair Taffa, whereas the gaseous fuel was used in a DJ 2700 equipment with a water-cooled 2700 DJHE model D-gun, both manufactured 
by Sulzer Metco. Table 1 shows the setup used in each case, which were those recommended by the suppliers of the equipment and consumables.

The different fuels, setups and equipment used meant that the metallic powders used in each case were different. Table 2 shows the chemical composition and nominal particle size for each powder; these consumables were supplied by the same manufacturers of the equipment used. Both have chemical compositions close to that designated for Inconel 625 alloys in ASTM B446 - 03(2014) ${ }^{14}$.

Two of the four available steel plates described earlier were coated by the gas fuel (GF) HVOF process while the other two were coated by liquid fuel (LF) HVOF. The measured final thickness of the HVOF GF coating was 270 $\mu \mathrm{m}$, whereas for HVOF LF a final thickness of $320 \mu \mathrm{m}$ was achieved. One plate of each was then subjected to a mechanical finishing process on a flat grinding machine at a wheel speed of $9 \mathrm{~m} \cdot \mathrm{s}^{-1}$ and a work speed of $0.1 \mathrm{~m} \cdot \mathrm{s}^{-1}$, with a down-feed per pass of $10 \mu \mathrm{m}$, with a straight, grit 60 alumina wheel, using a water-soluble light-duty oil as lubricant, in which $100 \mu \mathrm{m}$ of the thickness of the coating in total was removed. The thickness of the coatings was measured by the magnetic method described in ISO 2178, by use of a Politest equipment, model $1000 \mathrm{FS}$; resulting thicknesses were $170 \mu \mathrm{m}$ for the gas fuel HVOF, surface finished samples (GFSF), and $220 \mu \mathrm{m}$ for the liquid fuel HVOF, surface finished (LFSF) samples. Recommended total thicknesses of coatings before and after surface finishing were given by manufacturers, and are based on prior knowledge of their consumables, processes and application history.

\subsection{Residual stress analysis}

Residual stresses were measured by X-ray diffraction in a GE Seifert Charon equipment with a $\mathrm{Cr}-\mathrm{K} \alpha$ tube, in a $\psi$-configuration, with a primary aperture of $2 \mathrm{~mm}$ diameter, and a $20^{\circ} \mathrm{GE}$ Meteor 1D linear detector. Diffraction lines for the $\{220\}$ plane were then registered at 21 angles in the $-60^{\circ}<\psi<60^{\circ}$ range, each covering the $120^{\circ}<2 \theta<139^{\circ}$ range with a $0.1^{\circ}$ step and a time step of $40 \mathrm{~s}$. Measured diffraction lines were subjected to a background analysis with a B-spline function, and the central position of the lines was determined by use of the center of gravity method with a threshold of $80 \%{ }^{15}$. The slope of the linear regression through the measured data points gives the value of the residual stress. The standard deviation of the residual stress measurements stems from deviations of the X-ray diffraction line positions at 21 different angular positions ( $\Psi$-angles) to the calculated regression line. For the calculation of the residual stresses, the following parameters were considered: a Poisson ratio of 0.282 , a Young's modulus of $207 \mathrm{GPa}$, and elastic constants, $1 / 2 \mathrm{~s} 2$ of $6.190 \mathrm{E}-6 \mathrm{MPa}^{-1}$, and $-\mathrm{s} 1$ of 1.360E-6 $\mathrm{MPa}^{-1}$. Residual stresses were calculated by using the $\sin ^{2} \psi$ method in the GE Analyze software ${ }^{\circledR}$.

Residual stresses were measured superficially and also depth profiled. Surface measurements were taken at 5 randomly selected points of the surface of each sample (including the substrates prior to deposition). Depth profiles shown are the result of measurements performed on 5 samples taken from different regions of the coated steel plates. Electrochemical layer removal was used for profiling, with $1 \mathrm{~A}$ and $12 \mathrm{~V}$ applied for 1-5 min in a solution of $80 \% \mathrm{H}_{2} \mathrm{SO}_{4}$ and $20 \%$ of $\mathrm{H}_{3} \mathrm{PO}_{4}$. In profiles, residual stresses values were adjusted for layer removal by the method proposed by Moore and Evans in ${ }^{16}$.

\subsection{Corrosion tests}

Samples were subjected to electrochemical tests according to ASTM D1141-90 ${ }^{17}$. After the samples were inserted in synthetic seawater $(\mathrm{NaCl} 3.5 \%)$, the open circuit potential (OCP) was monitored for $700 \mathrm{~s}$, after which potentiodynamic polarization was performed $(-1500 \mathrm{mV}$ to $+1500 \mathrm{mV}$ relative to OCP, scanning rate of $1 \mathrm{mV} \cdot \mathrm{s}^{-1}$, exposed area of $1 \mathrm{~cm}^{2}$ ).

Table 1. Process parameters for each condition of Inconel coating application.

\begin{tabular}{lcc}
\hline & HVOF GF (gas fuel) & HVOF LF (liquid fuel) \\
\hline Powder type (Manufacturer) & Diamalloy 1005 (Praxair Taffa) & $1265 \mathrm{~F}$ (Sulzer Metco) \\
Fuel type & Propane & Kerosene \\
Fuel pressure & $0.62 \mathrm{MPa}$ & $0.875 \mathrm{MPa}$ \\
Fuel flux & $1.57 \mathrm{~L} / \mathrm{s}$ & $0.006 \mathrm{~L} / \mathrm{s}$ \\
Oxygen pressure & $1.17 \mathrm{MPa}$ & $0.951 \mathrm{MPa}$ \\
Oxygen flux & $5.5 \mathrm{~L} / \mathrm{s}$ & $14.5 \mathrm{~L} / \mathrm{s}$ \\
Application distance & $0.22 \mathrm{~m}$ & $0.38 \mathrm{~m}$ \\
\hline
\end{tabular}

Table 2. Chemical composition of metallic powder used for Inconel coating production.

\begin{tabular}{lcccccc}
\hline \multirow{2}{*}{ Process } & \multirow{2}{*}{ Powder } & \multicolumn{3}{c}{ Chemical composition (\%wt) } & \multicolumn{2}{c}{ Nominal particle size } \\
\cline { 3 - 6 } & & Cr & Mo & Ni & Other & \\
\hline HVOF LF (liquid fuel) & $1265 \mathrm{~F}$ & 21.5 & 9.0 & 65.8 & $3.7(\mathrm{Nb}+\mathrm{Ta})$ & $53 \pm 22$ \\
HVOF GF (gas fuel) & Diamalloy 1005 & 21.5 & 8.5 & 67.0 & $3.0(\mathrm{Fe})$ & $45 \pm 11$ \\
\hline
\end{tabular}




\subsection{Coating characterization}

Coatings were characterized by metallographic crosssectioning, optical and scanning electron microscopy (SEM), and energy dispersive X-ray spectroscopy (EDX). Roughness values of the coatings were measured according to ISO 4220:1997 and will be given as $\mathrm{R}_{\mathrm{a}}$ (arithmetical mean deviation of the assessed profile) and $R_{t}$ (sum of height of the largest profile peak height and the largest profile valley depth within an evaluation length).

\section{Results and Discussion}

\subsection{Residual stresses and coating characterization}

XRD residual stress measurements were initially taken at 5 randomly selected points of the surface of each of the shot-blasted AISI 4140 steel plates which were used as substrates. Results are shown in Table 3. Similar stress values, of a compressive nature, were found on all 4 plates; results gave mean values of -231 MPa in the longitudinal direction and -228 MPa in the transversal direction, and a standard deviation of $18 \mathrm{MPa}$ and $26 \mathrm{MPa}$ in each direction, respectively. Values of FWHM (Full Width at Half Maximum), which indicate the presence of second order residual stresses and are related to plastic deformation and lattice distortion ${ }^{18}$, were of $3.61^{\circ}$ in the longitudinal direction and $3.66^{\circ}$ in the transversal direction, with standard deviation values of $0.07^{\circ}$ in both directions. This means that the shot-blasting of the sample, prior to deposition of the Inconel coatings, was uniform. The main purpose of the shot-blasting process in this work was to produce an increased superficial roughness of the steel substrate in order to improve coating adhesion.

The residual stress measurement procedure was repeated on the surface of samples coated with the GF (gaseous fuel, no surface finishing) and LF (liquid fuel, no surface finishing) processes. Table 3 shows the results: all measurements indicated that stresses in these cases are tensile. For GF samples a mean value of $64 \mathrm{MPa}$ in the longitudinal direction and 68 MPa in the transversal direction, with standard deviation values of $34 \mathrm{MPa}$ and $24 \mathrm{MPa}$ in each of the directions, respectively, were found. For LF samples, a mean value of $43 \mathrm{MPa}$ was found in the longitudinal direction and of 10 MPa in the transversal direction, with standard deviation values of $8 \mathrm{MPa}$ and $2 \mathrm{MPa}$, respectively.

When the results for GF and LF samples in Table 3 are compared, one can see that LF coatings develop lower residual stresses which are more uniformly distributed (as indicated by the lower standard deviation values). LF coated samples also show significant dependency of residual stress values on the direction of application of the coating. GF coatings, on the other hand, show relatively higher residual stress values, a less marked dependency on direction of application compared to the LF condition, and a less uniform residual stress distribution. These differences were expected since the two processes are essentially dissimilar in terms of parameters and of many characteristics of the resulting coatings (oxide content, porosity, etc.).

Table 3 also shows the results of residual stress measurements on the surface of samples coated with the GFSF (gaseous fuel, surface finished) and LFSF (liquid fuel, surface finished) processes. For GFSF, stresses are of compressive nature, with a mean value of $-844 \mathrm{MPa}$ in the longitudinal direction and $-380 \mathrm{MPa}$ in the transversal direction, with standard deviation values of $71 \mathrm{MPa}$ and 137 MPa, respectively. For LFSF, a mean value of -703 MPa was found in the longitudinal direction and of -150 MPa in the transversal direction, with standard deviation values of 102 $\mathrm{MPa}$ and $54 \mathrm{MPa}$, respectively. The surface finishing step therefore leads to a significant compressive stress state at the surface of the samples, with significant loss of uniformity of the residual stress distribution in the coating, and strong influence of the grinding direction. The FWHM values for GFSF and LFSF in Table 3 are higher than those seen for GF and LF, and although not as high as the ones obtained for the shot-blasted substrate, they indicate that significant plastic deformation and lattice distortion occurred during the process.

For GF and LF samples, the residual stress distribution at the surface is thought to be a more significant issue than depth profiles, since the residual stress values up to a depth of around $80 \mu \mathrm{m}$ varied by less than $20 \%$ of the mean of the superficial residual stress values shown in Table 3 . The

Table 3. Results of residual stress measurements at surface.

\begin{tabular}{|c|c|c|c|c|}
\hline \multirow{3}{*}{ Condition } & \multicolumn{4}{|c|}{ Direction of measurement } \\
\hline & \multicolumn{2}{|c|}{ Longitudinal } & \multicolumn{2}{|c|}{ Transversal } \\
\hline & $\begin{array}{c}\text { Mean residual stress } \\
(\mathrm{MPa})\end{array}$ & Mean FHWM ( $\left.{ }^{\circ}\right)$ & $\begin{array}{c}\text { Mean residual stress } \\
(\mathrm{MPa})\end{array}$ & Mean FHWM $\left({ }^{\circ}\right)$ \\
\hline Shot-blasted AISI 4140 & $-231 \pm 18$ & $3.61 \pm 0.07$ & $-228 \pm 26$ & $3.66 \pm 0.07$ \\
\hline GF & $64 \pm 34$ & $2.23 \pm 0.07$ & $68 \pm 24$ & $2.19 \pm 0.07$ \\
\hline LF & $43 \pm 8$ & $2.08 \pm 0.10$ & $10 \pm 2$ & $1.99 \pm 0.05$ \\
\hline GFSF & $-844 \pm 71$ & $2.73 \pm 0.09$ & $-380 \pm 137$ & $2.86 \pm 0.06$ \\
\hline LFSF & $-703 \pm 102$ & $2.64 \pm 0.10$ & $-150 \pm 54$ & $2.66 \pm 0.11$ \\
\hline
\end{tabular}

GF - gas fuel, LF - liquid fuel, GFSF - gas fuel, surface finished, LFSF - liquid fuel, surface finished 
tendency of residual stress depth profiles in these samples is similar to those seen for as-deposited HVOF Inconel coatings in ${ }^{19}$. On the other hand, significant variation was seen in the residual stress depth profiles obtained for GFSF and LFSF samples, and typical profiles are therefore shown in Figure 1. Profiles in the longitudinal (grinding) direction can be seen in Figure 1a, along with their correspondent FWHM values, whereas Figure 1b shows the residual stress profiles and FWHM values in the transversal direction. As data in Table 3 indicates, superficial compressive residual stresses are found for both surface finished conditions, in both directions. Values of residual stresses fall rapidly with increasing depth for samples in the GFSF, and at around 20 $\mu \mathrm{m}$ they are approximately constant, at around $-100 \mathrm{MPa}$, throughout the remaining analysed depth. For samples in the LFSF condition, values of compressive residual stresses remained at relatively higher values up to depths of at least $70 \mu \mathrm{m}$ in both directions. These differences in the profiles are partially influenced by the coating thickness (see ${ }^{11}$ for a more detailed overview of the mechanisms involved in residual stress build-up), but mostly due to the inherent differences between the two methods and even small differences between particle sizes, which lead to different splat morphologies, porosity levels and oxide contents; these characteristics of the coatings consequently affect the levels of plastic deformation which are experienced by the coating during the surface finishing process.

In all surfaced finished samples, the surface residual stress values, and the subsurface values up to a depth of at least $20 \mu \mathrm{m}$, were greater in the grinding direction (longitudinal) than in the transversal direction. This effect, as well as the general tendency of residual stress depth profiles in these samples, is in agreement with previous results published in the literature ${ }^{20,21}$.

The superficial roughness of the coatings was measured and is shown in Table 4; values indicate that unfinished samples (GF and LF) had approximately the same degree of roughness, independently of the type of fuel and process used to produce their coatings. Roughness values for GF and LF samples are dependent on the direction of application of the coating, which was always in the longitudinal direction. Values also show that surface finishing leads to considerably smoother surfaces, which indicates that individual lamellas have either been removed or deformed, and that the presence of oxide particles and open pores has been reduced. Surface finishing was performed in the longitudinal direction, but this does not seem to affect roughness directionality (in GFSF and LFSF samples) as much as deposition direction does (in GF and LF samples).

The surface of the coatings after deposition shows a lamellar morphology, with some discontinuities and oxides as can be seen in Figure 2. The GF coating in Figure 2a shows smaller lamellas compared to those seen in the LF coating (Figure $2 b)$. Several open pores are seen in both images. Figure $3 \mathrm{a}$ shows cross-sections of the LFSF and GFSF coatings, and Figure $3 \mathrm{~b}$ shows the interface between the substrate and the coating. EDX analysis was performed both on individual splats and on splat boundaries (points 1 and 2, respectively, in Figure 3b); typical spectra are seen in: Figure 4a, for a splat, where high levels of oxygen, niobium, chromium and nickel are seen, and Figure $4 b$, for a splat boundary, where only elements present in the chemical composition of the powder are seen. This confirmed that significant oxide levels were incorporated in both coatings; as seen in Figures 3a and $3 \mathrm{~b}$, this occurred more markedly in GF coatings. Figure 5 shows images of the surfaces of coatings in the GFSF and LFSF conditions, and reveals that after the grinding process sample surfaces presented a series of machining marks; in coatings obtained from gaseous fuel these marks were more pronounced, as also is indicated by the higher $\mathrm{R}_{\mathrm{t}}$ roughness values in Table 4. Nevertheless, it is clear from the images in Figure 5, especially when compared to those of Figure 2,

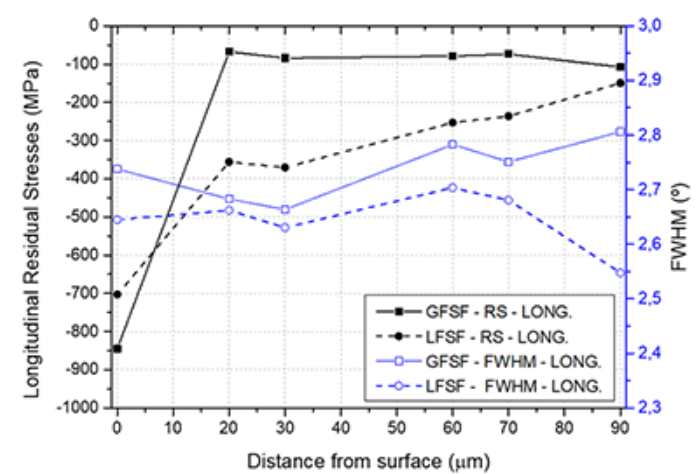

(A)

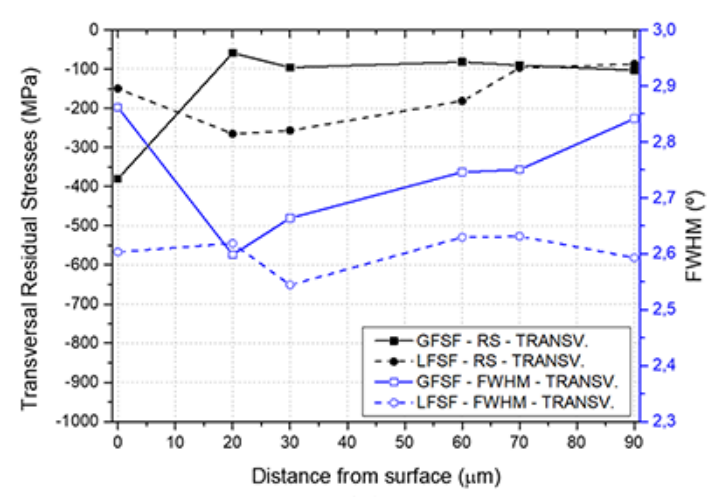

(B)

Figure 1. Residual stresses (RS) and Full Width at Half Maximum (FWHM) depth profiles for GFSF (gaseous fuel, with surface finishing) and LFSF (liquid fuel, with surface finishing) samples. (a) Longitudinal direction (Long.); (b) Transversal direction (Transv.). Samples were both coated and surface finished in the longitudinal direction. 
Table 4. Measured roughness values (in $\mu \mathrm{m}$ ) for the four HVOF Inconel coating conditions, in the longitudinal (L) and transversal (T) directions. Coating application and surface finishing directions were always in the longitudinal direction.

\begin{tabular}{lccccccccc}
\hline Condition & \multicolumn{3}{c}{ GF } & \multicolumn{3}{c}{ GFSF } & \multicolumn{2}{c}{ LF } & \multicolumn{2}{c}{ LFSF } \\
\hline Direction & $\mathrm{L}$ & $\mathrm{T}$ & $\mathrm{L}$ & $\mathrm{T}$ & $\mathrm{L}$ & $\mathrm{T}$ & $\mathrm{L}$ & $\mathrm{T}$ \\
\cline { 2 - 9 } & & & & Roughness $(\mu \mathrm{m})$ & & & \\
$\mathrm{Ra}$ & 11.68 & 7.30 & 0.47 & 0.30 & 11.44 & 12.48 & 0.55 & 0.26 \\
$\mathrm{Rt}$ & 87.32 & 61.84 & 9.71 & 7.31 & 88.75 & 70.20 & 5.90 & 5.00 \\
\hline
\end{tabular}

GF-gas fuel, GFSF-gas fuel surface finished, LF-liquid fuel, LFSF-liquid fuel surface finished.

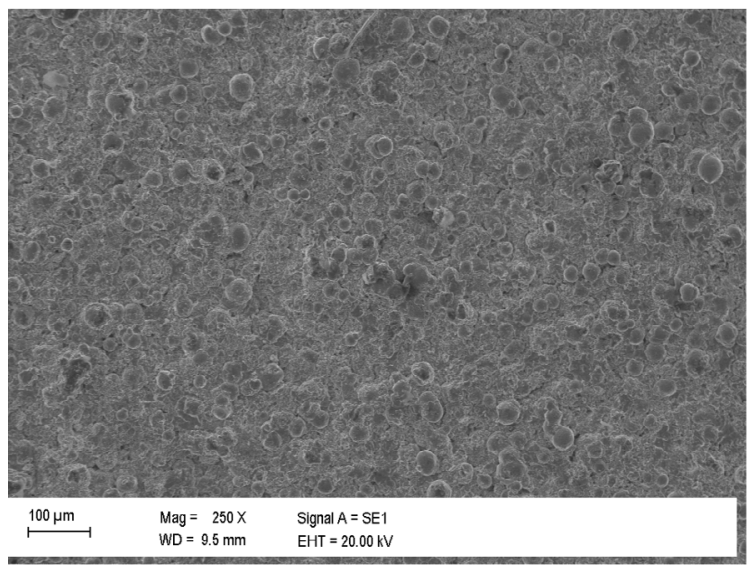

(A)

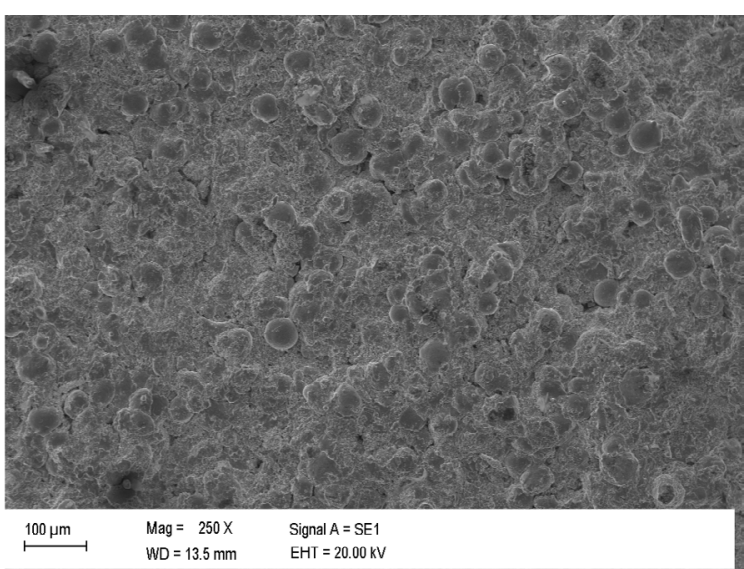

(B)

Figure 2. Surface morphology of the as-deposited coatings obtained from: (a) gaseous fuel (GF); (b) liquid fuel (LF).

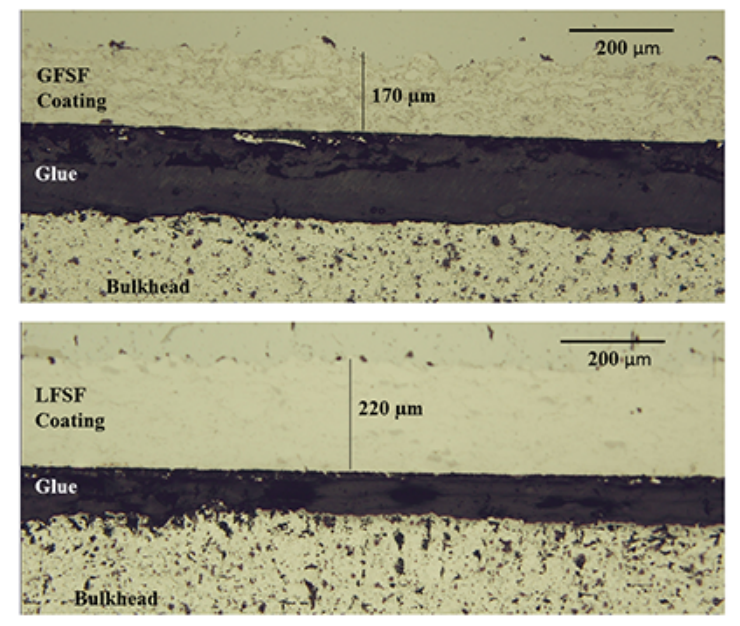

(A)

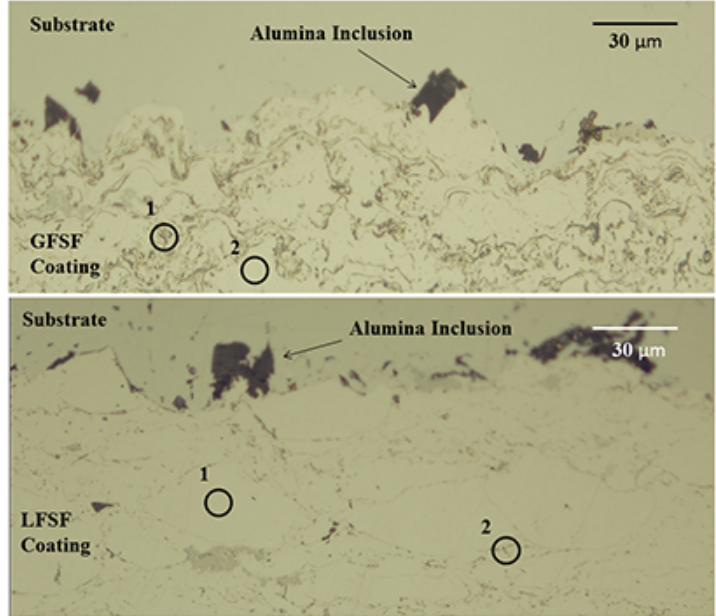

(B)

Figure 3. (A) Metallographic cross-sections of coated samples; (B) Substrate-coating interface showing points 1 (on splat) and 2 (on splat boundary) in which EDX analysis was performed.

that grinding leads to a smoother surface (as also indicated by roughness values in Table 4). Residual stress results in Figure 1 and Table 3 help to indicate that this is due to plastic deformation at the surface of samples during grinding.

\subsection{Corrosion testing}

Figure 6a shows the polarization curves of the samples in GF and LF conditions; slightly higher values of corrosion potential are seen for coatings obtained from gaseous fuel HVOF (GF). In both cases, corrosion potential values are much lower than those expected for dense Inconel coatings, which are typically around $-250 \mathrm{mV}_{\mathrm{SCE}}^{22}$. Instead, the values reached the potential of AISI 4140, which is around -600 $\mathrm{mV}_{\mathrm{SCE}}{ }^{23}$. This is due to the presence of porosity (as seen in Figures 2 and 3 ) which limits the protective barrier effect of these coatings, regardless of the type of fuel used. As 


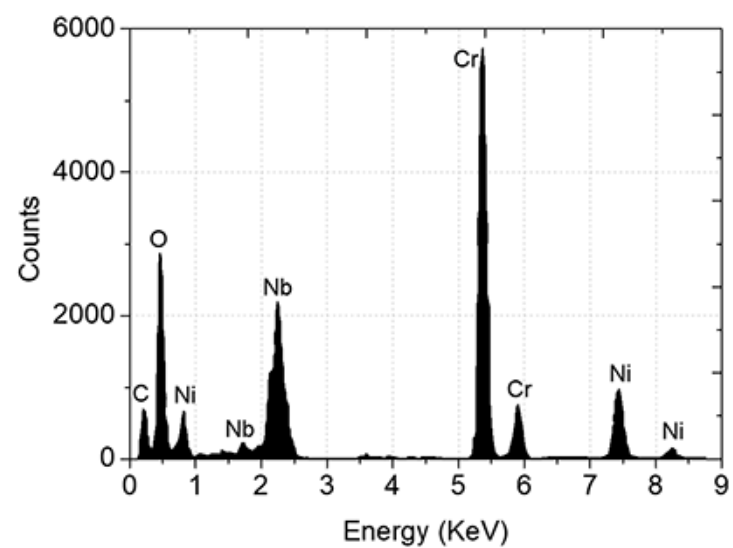

(A)

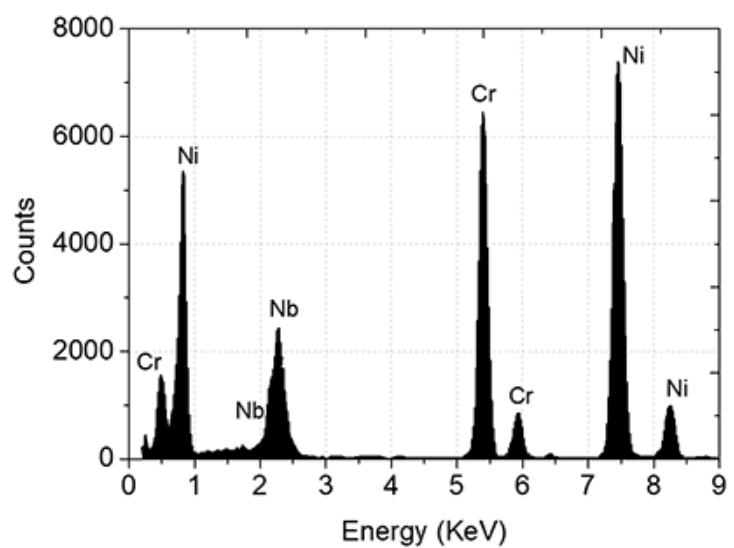

(B)

Figure 4. Typical energy dispersive X-ray spectroscopy (EDX) results on: (A) region 1; (B) region 2, in Figure 3.

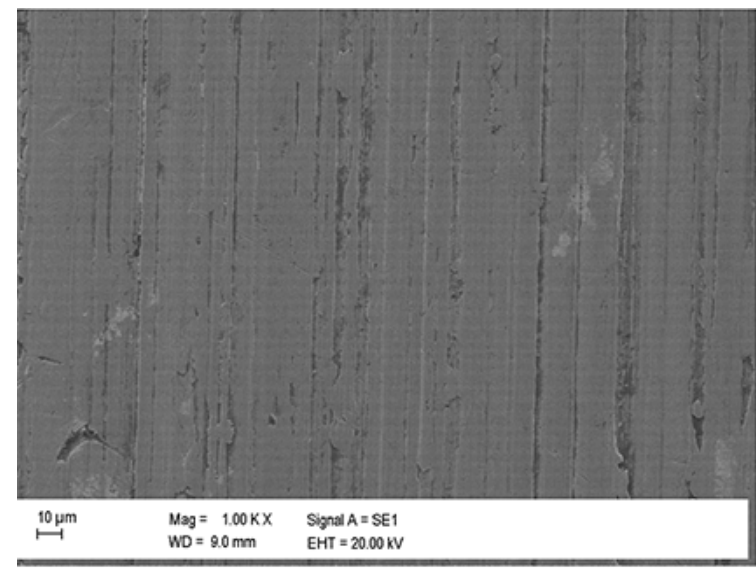

(A)

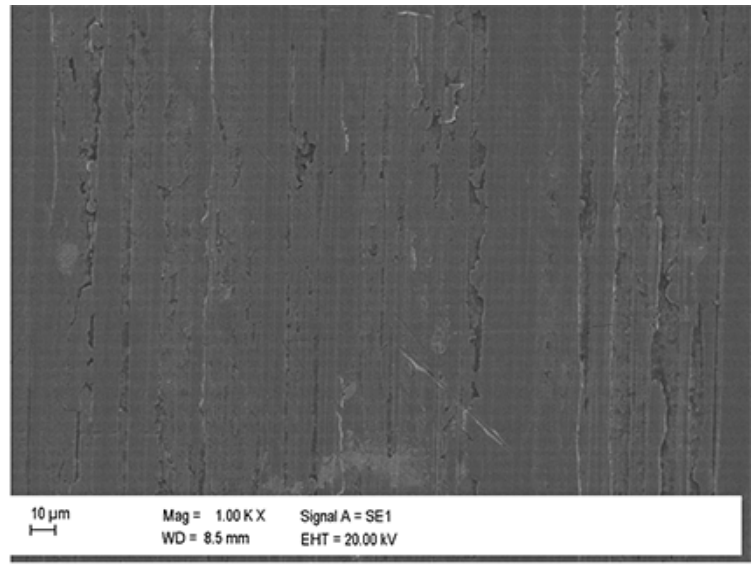

(B)

Figure 5. Surface morphology of the coatings after the grinding process, obtained from: (a) gaseous fuel (GFSF); (b) liquid fuel (LFSF).

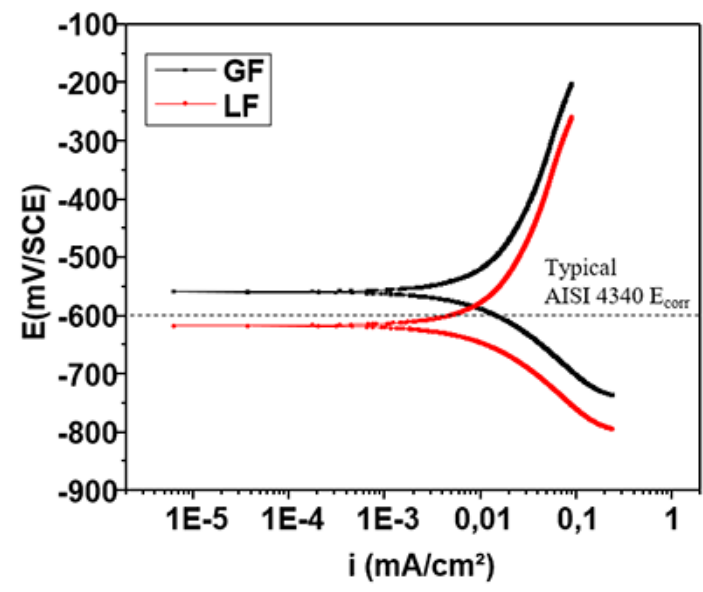

(A)

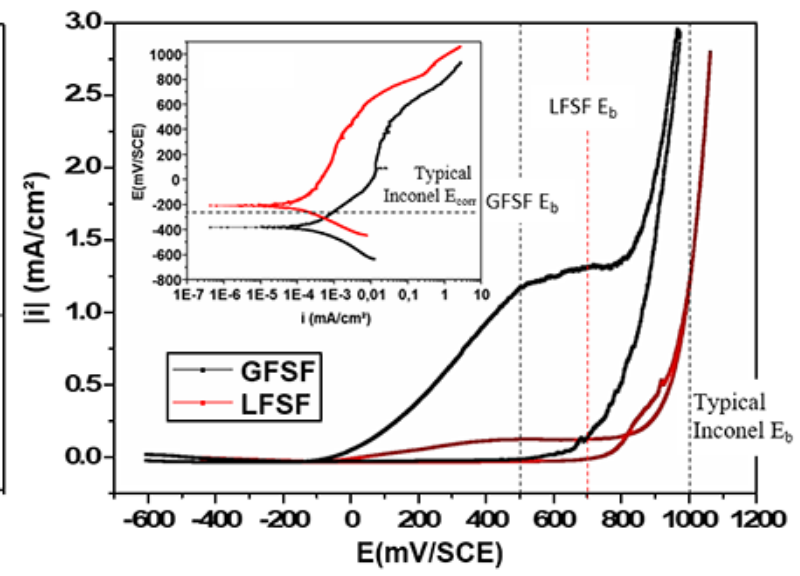

(B)

Figure 6. Potentiodynamic polarization curves of: a) the as deposited coatings, b) coatings after the grinding process. Tests performed in $\mathrm{NaCl} 3.5 \%$, scan rate $1 \mathrm{mV} \cdot \mathrm{s}^{-1}$. 


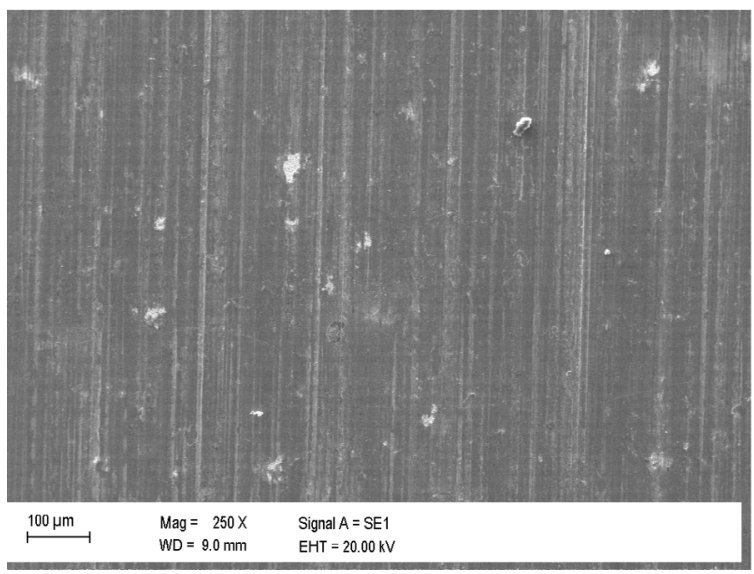

(A)

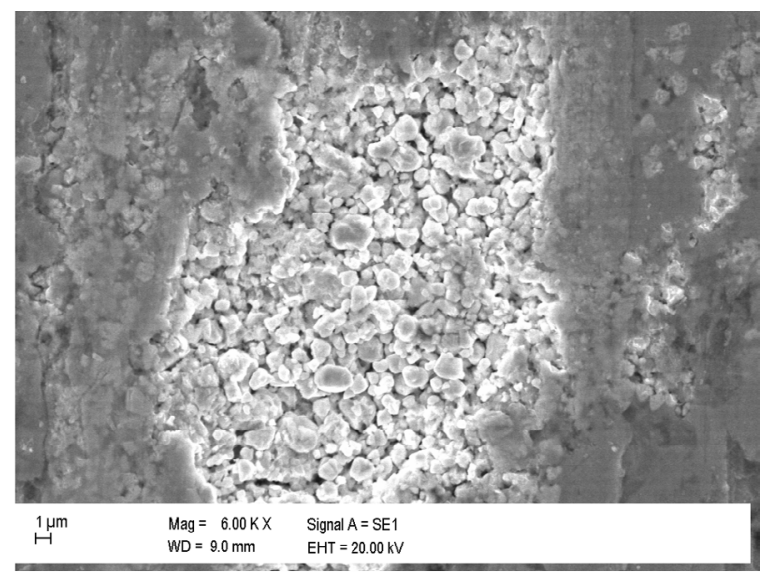

(B)

Figure 7. Surface morphology of surface finished samples after corrosion tests: (A) gaseous fuel (GFSF); (B) magnification of localized corrosion seen in (A).

can be seen in Figure 6, coatings obtained with gaseous fuel (GF) developed substantially higher corrosion current densities than those obtained with liquid fuel (LF), indicating that GF allows better protection of the substrate under these conditions. Also in the anodic region, a substantial increase in current is seen for the coating obtained by LF. As reported in the literature ${ }^{6,7}$ the higher oxidation rate seen after deposition for GF coatings (which is confirmed by metallography, in Figure 3, and EDX analysis results, in Figure 4a) could lead to a partial coverage of porosities, inducing an improvement in corrosion protection through a partial physical barrier mechanism.

When the coatings have undergone the surface finishing process, significant changes to their corrosion characteristics are seen. While samples in LF and GF conditions show corrosion potentials close to those expected for the substrate in the tested environment, samples in GFSF and LFSF conditions showed a shift in corrosion potentials to more positive values, which are closer to expected values for dense Inconel, an effect which is especially prominent in the LFSF system (Figure 6b). The corrosion current densities were also much lower for samples in GFSF and LFSF conditions (in the order of $10^{-4} \mathrm{~mA} / \mathrm{cm}^{2}$ ) when compared with the as-deposited LF and GF conditions, which presented corrosion current densities around $10^{-2}-10^{-3} \mathrm{~mA} / \mathrm{cm}^{2}$. Surface finishing seems also to modify the corrosion mechanisms involved. GF and LF conditions exhibited general corrosion mechanisms, which were due to the excessive porosity and resulting exposure of the substrate to the environment. Surface finished conditions samples (LFSF and GFSF) showed a behavior typical of localized corrosion, with low current density until the breakdown potential $\left(\mathrm{E}_{\mathrm{b}}\right.$, which is shown in Figure $6 b$ for LFSF, GFSF and dense Inconel) and then a more intense corrosion process. These differences in corrosion behavior are thought to be related to the surface densification which occurs after the grinding process, through a plastic deformation mechanism, which reduces the surface porosity by closing open-to-surface pores, and also leads to the significantly lower roughness values seen in Table 4. A breakdown potential of around $500 \mathrm{mV}$ is seen in Figure $6 \mathrm{~b}$ for the coating obtained from gaseous fuel (GFSF), whereas for the coatings obtained from liquid fuel (LFSF) the breakdown potential was observed at around $700 \mathrm{mV}$, while the breakdown potential for dense Inconel is around $1000 \mathrm{mV}$. Both systems showed high return hysteresis in cyclic voltammetry, indicating difficult surface repassivation; hysteresis of this magnitude are usually associated with highly localized corrosion. Images of the surface of the samples after the cyclic voltammetry showed localized corrosion points in the vicinity of machining marks; this was much more evident in the coatings obtained from gaseous fuel (GFSF, see Figure 7a) than in those obtained from liquid fuel (LFSF). In these localized corrosion points the shallow densified surface layer breaks down to reveal a structure which is reminiscent of that which is found on the surface of as-deposited samples, which have not undergone plastic deformation by grinding (see magnification of Figure 7a in Figure $7 b$ ). This effect explains the increased corrosion rates after breakdown potential are achieved, and the difficult repassivation of the coating from then onwards.

\section{Conclusions}

Residual stress and surface roughness values and metallographic analysis indicate that surface finishing by grinding of Inconel 625 coatings applied to AISI 4140 steel substrates by two different HVOF processes causes plastic deformation of the surface of the coating, leading to densification of a shallow surface layer by effectively deforming individual lamella and closing pores which were initially open to the surface. 
This effect leads to a remarkable improvement in corrosion resistance, with results showing that corrosion potentials close to those encountered for dense Inconel are achieved; it should be noted, however, that long-term corrosion resistance under operational conditions must still be evaluated. On the other hand, as-deposited coatings produced by the same two HVOF processes exhibited poor corrosion performance, with corrosion potentials close to those found for unprotected AISI 4140 steels, which shows that coating porosity, which is inherent to the process, connects the surface to the substrate and leads to ineffective corrosion protection. Corrosion tests and metallography also show different corrosion characteristics when as-deposited and surface finished samples are compared, the former exhibiting generalized corrosion behavior, whereas the latter undergoes localized corrosion, particularly at machining marks, through a breakdown mechanism of the shallow densified layer. Although it is known that careful process parameter adjustment can improve the density of coatings, these results indicate that a finishing process can be useful to guarantee a denser, plastically-deformed surface layer, which reduces the quantity of open-to-surface pores.

\section{References}

1. Davis JR. Handbook of Thermal Spray Technology. Materials Park: ASM International; 2004

2. Wielage B, Wank A, Pokhmurska H, Grund T, Rupprecht C, Reisel G, et al. Development and trends in HVOF spraying technology. Surface and Coatings Technology. 2006;201(5):20322037. DOI: 10.1016/j.surfcoat.2006.04.049

3. Al-Fadhli HY, Stokes J, Hashmi MSJ, Yilbas BS. The erosioncorrosion behaviour of high velocity oxy-fuel (HVOF) thermally sprayed inconel-625 coatings on different metallic surfaces. Surface and Coatings Technology. 2006;200(20-21):5782-5788. DOI: 10.1016/j.surfcoat.2005.08.143

4. Hanson TC, Settles GS. Particle temperature and velocity effects on the porosity and oxidation of an HVOF corrosion-control coating. Journal of Thermal Spray Technology. 2003;12(3):403415. DOI: $10.1361 / 105996303770348276$

5. Stewart DA, Shipway PH, McCartney DG. Abrasive wear behavior of conventional and nanocomposite HVOF-sprayed WC-Co coatings. Wear. 1999;225-229(Pt 2):789-798. DOI: 10.1016/S0043-1648(99)00032-0

6. Baskare MS, Voisey KT, Roe MJ, McCartney DG. X-ray photoelectron spectroscopy study of the passive films formed on thermally sprayed and wrought Inconel 625. Applied Surface Science. 2010;257(3):786-794. DOI: 10.1016/j.apsusc.2010.07.066

7. Zhang D, Harris SJ, McCartney DG. Microstructure formation and corrosion behaviour in HVOF-sprayed Inconel 625 coatings. Materials Science and Engineering: A. 2003;344(1-2):45-56. DOI: $10.1016 / \mathrm{S} 0921-5093(02) 00420-3$

8. Scrivani A, Ianelli S, Rossi A, Groppetti R, Casadei F, Rizzi G. A contribution to the surface analysis and characterization of HVOF coatings for petrochemical application. Wear. 2001;250(12):107-113. DOI: 10.1016/S0043-1648(01)00621-4
9. Edris H, McCartney DG, Sturgeon AJ. Microstructural characterization of high velocity oxy-fuel sprayed coatings of Inconel 625. Journal of Materials Science. 1997;32(4):863-872. DOI: 10.1023/A:1018589230250

10. Arif AFM, Yilbas BS. Three-point bend testing of HVOF Inconel 625 coating: FEM simulation and experimental investigation. Surface and Coatings Technology. 2006;201(3-4):1873-1879. DOI: $10.1016 /$ j.surfcoat.2006.03.016

11. Varis T, Suhonen T, Ghabchi A, Valarezo A, Sampath S, Liu X, et al. Formation Mechanisms, Structure, and Properties of HVOFSprayed WC-CoCr Coatings: An Approach Toward Process Maps. Journal of Thermal Spray Technology. 2014;23(6):1009-1018.

12. Goeke S, Brüggemann T, Biermann D. Development of Machining Processes for the Use of Multilayer High-Performance Coatings. ISRN Tribology. 2013;2013:750251. DOI: 10.5402/2013/750251

13. Murthy JKN, Rao DS, Venkataraman B. Effect of grinding on the erosion behavior of a WC-Co-Cr coating deposited by HVOF and detonation gun spray processes. Wear. 2001;249(7):592600. DOI: 10.1016/S0043-1648(01)00682-2

14. ASTM International. ASTM B446-03 - Standard Specification for Nickel-Chromium-Molybdenum-Columbium Alloy (UNS N06625), Nickel-Chromium-Molybdenum-Silicon Alloy (UNS N06219), and Nickel-Chromium-Molybdenum-Tungsten Alloy (UNS N06650) Rod and Bar. West Conshohocken: ASTM International; 2014.

15. Hauk V. Structural and Residual Stress Analysis by Nondestructive Methods: Evaluation - Application - Assessment. Amsterdam: Elsevier Science; 1997.

16. Moore MG, Evans WP. Mathematical Correction for Stress in Removed Layers in X-ray Diffraction Residual Stress Analysis. SAE Technical Paper580035. 1958. DOI: 10.4271/580035

17. ASTM International. ASTM G5-14 - Standard Reference Test Method for Making Potentiodynamic Anodic Polarization Measurements. West Conshohocken: ASTM International; 2014.

18. Balart MJ, Bouzina A, Edwards L, Fitzpatrick ME. The onset of tensile residual stresses in grinding of hardened steels. Materials Science and Engineering: A. 2004;367(1-2):132-142. DOI: $10.1016 /$ j.msea.2003.10.239

19. Lyphout C, Nylén P, Manescu A, Pirling T. Residual Stresses Distribution through thick HVOF Sprayed Inconel 718 Coatings. Journal of Thermal Spray Technology. 2008;17(5-6):915-923. DOI: $10.1007 / \mathrm{s} 11666-008-9242-9$

20. Fergani O, Shao Y, Lazoglu I, Liang SY. Temperature Effects on Grinding Residual Stress. Procedia CIRP. 2014;14:2-6. DOI: 10.1016/j.procir.2014.03.100

21. Brinksmeier E, Cammett JT, König W, Leskovar P, Peters J, Tönshoff HK. Residual Stresses - Measurement and Causes in Machining Processes. CIRP Annals. 1982;31(2):491-510. DOI: $10.1016 / \mathrm{S} 0007-8506(07) 60172-3$

22. Karthik D, Swaroop S. Laser shock peening enhanced corrosion properties in a nickel based Inconel 600 superalloy. Journal of Alloys and Compounds. 2017;694:1309-1319.DOI: 10.1016/j.jallcom.2016.10.093

23. Mirjani M, Mazrooei J, Karimzadeh N, Ashrafizadeh F. Investigation of the effects of time and temperature of oxidation on corrosion behavior of plasma nitrided AISI 4140 steel. Surface and Coatings Technology. 2012;206(21):4389-4393. DOI: $10.1016 /$ j.surfcoat.2012.04.064 